Supplement of

\title{
Online single particle analysis of ice particle residuals from mountain-top mixed-phase clouds using laboratory derived particle type assignment
}

Susan Schmidt et al.

Correspondence to: Johannes Schneider (johannes.schneider@mpic.de)

The copyright of individual parts of the supplement might differ from the CC-BY 3.0 licence. 
This supplement shows the laboratory mass reference mass spectra that were used to infer characteristic marker peaks for a number of particle types.

Figures S1 through S12 show the data sampled at MPIC, Figures S13 though S20 those measured at the AIDA facility of KIT. The mass spectra obtained from one particle type were clustered using the fuzzy c-means algorithm as explained in the main text. Typically, the largest cluster (the most frequent spectrum type) is shown and the percentage of spectra contained in this largest cluster is given. In certain cases, the two or three largest clusters are shown, giving an indication on the variability of mass spectra from one particle type. 

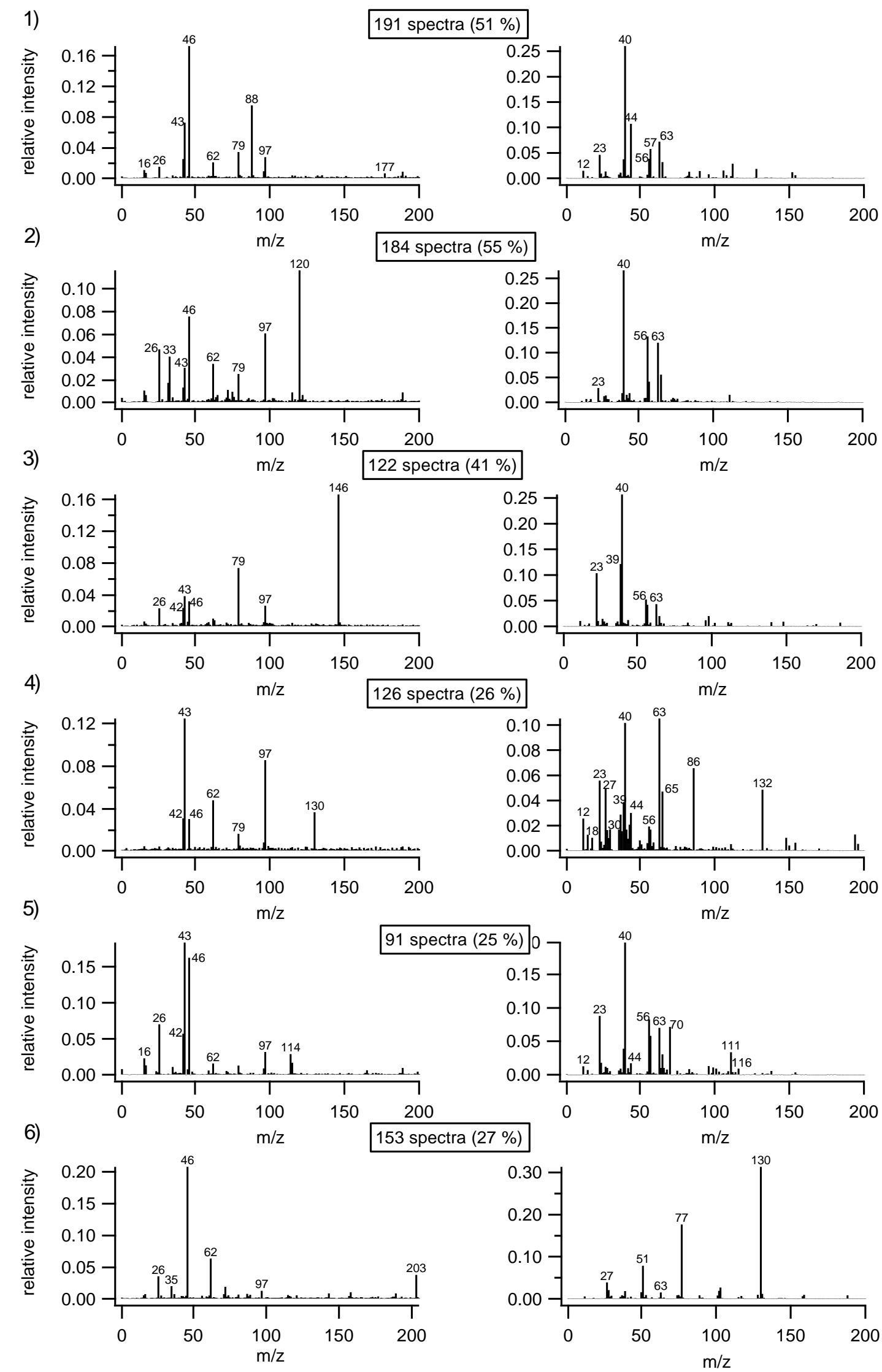

Figure S1: Average spectra of different amino acids from laboratory measurements at MPIC: 1) alanine; 2) cysteine; 3) glutamic acid; 4) leucine; 5) proline; 6) tryptophan. 

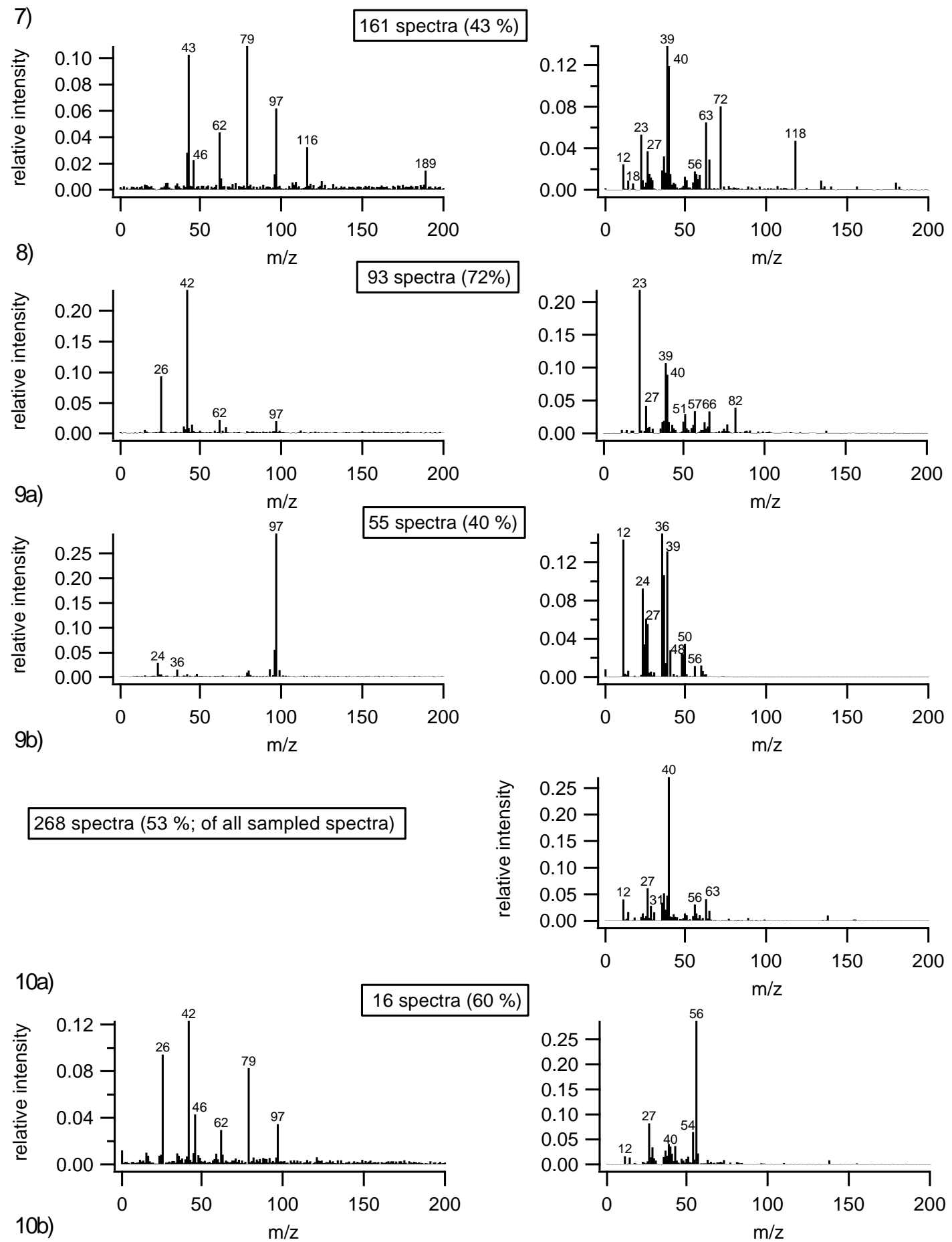
$\mathrm{m} / \mathrm{z}$

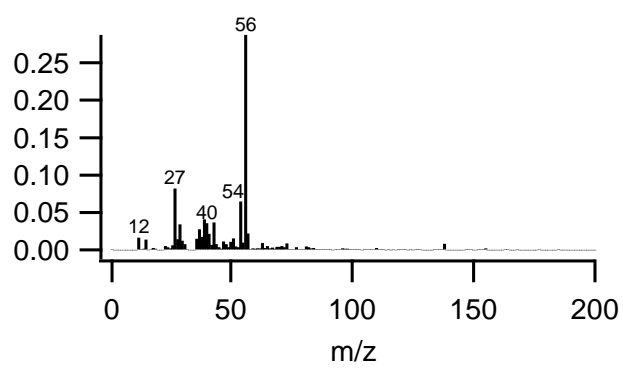

281 spectra (53\%; of all sampled spectra)

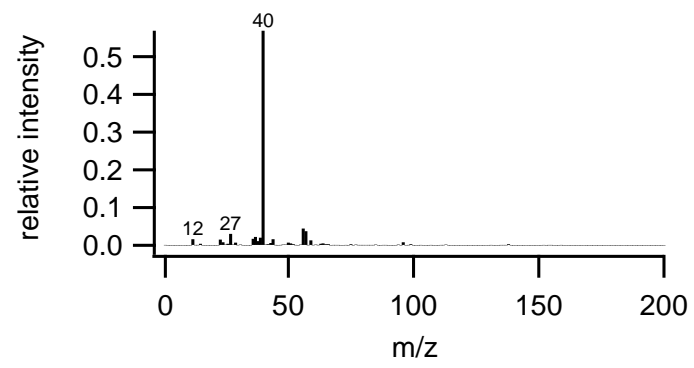

Figure S2: Average spectra of different substances biological origin from laboratory measurements at MPIC: 7) valine; 8) riboflavin; 9) glucose; 10) sucrose. 

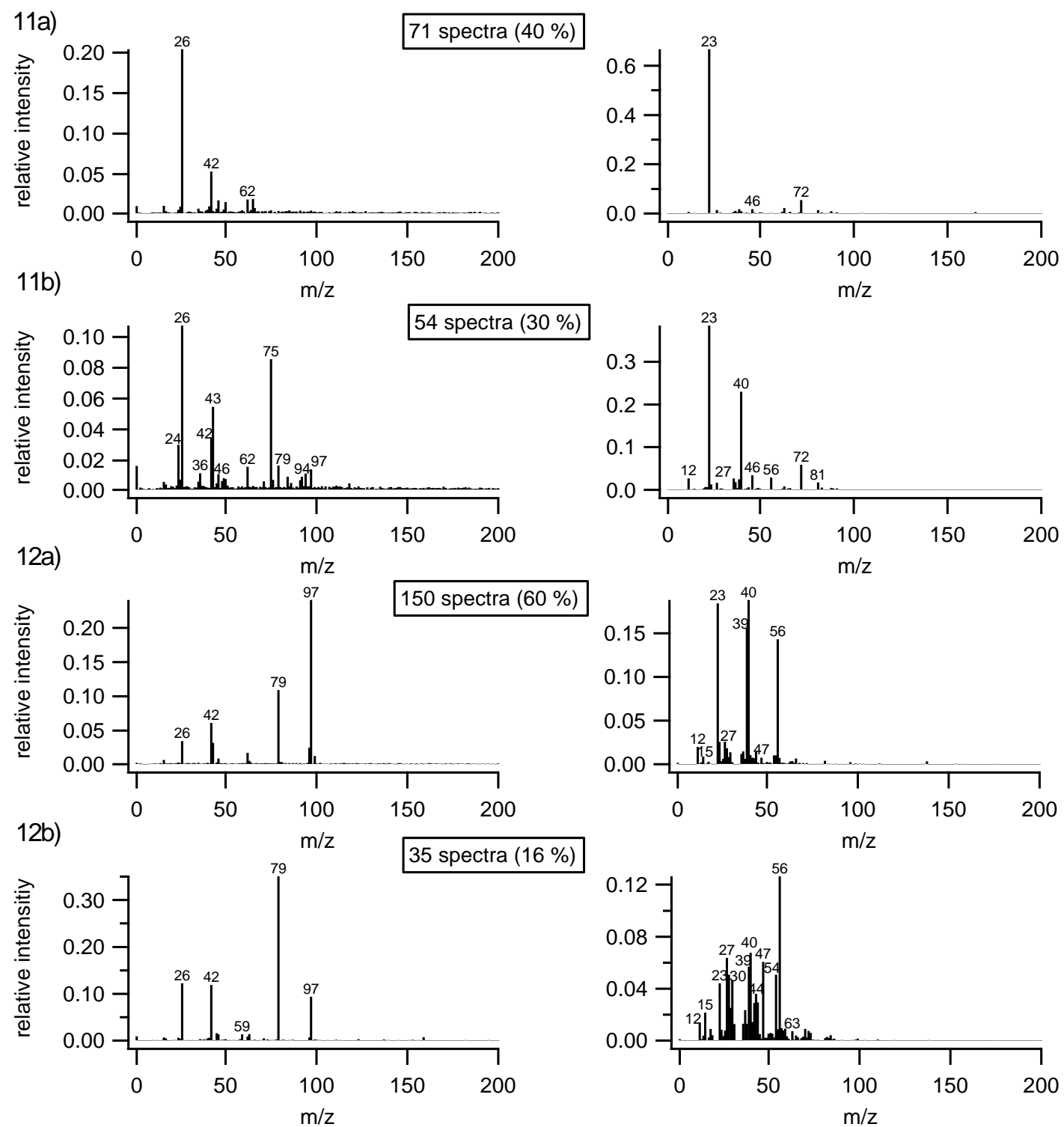

Figure S3: Average spectra of protein measurements from the laboratory measurements at MPIC: 11) chlorophyll; 12) hemoglobin. 

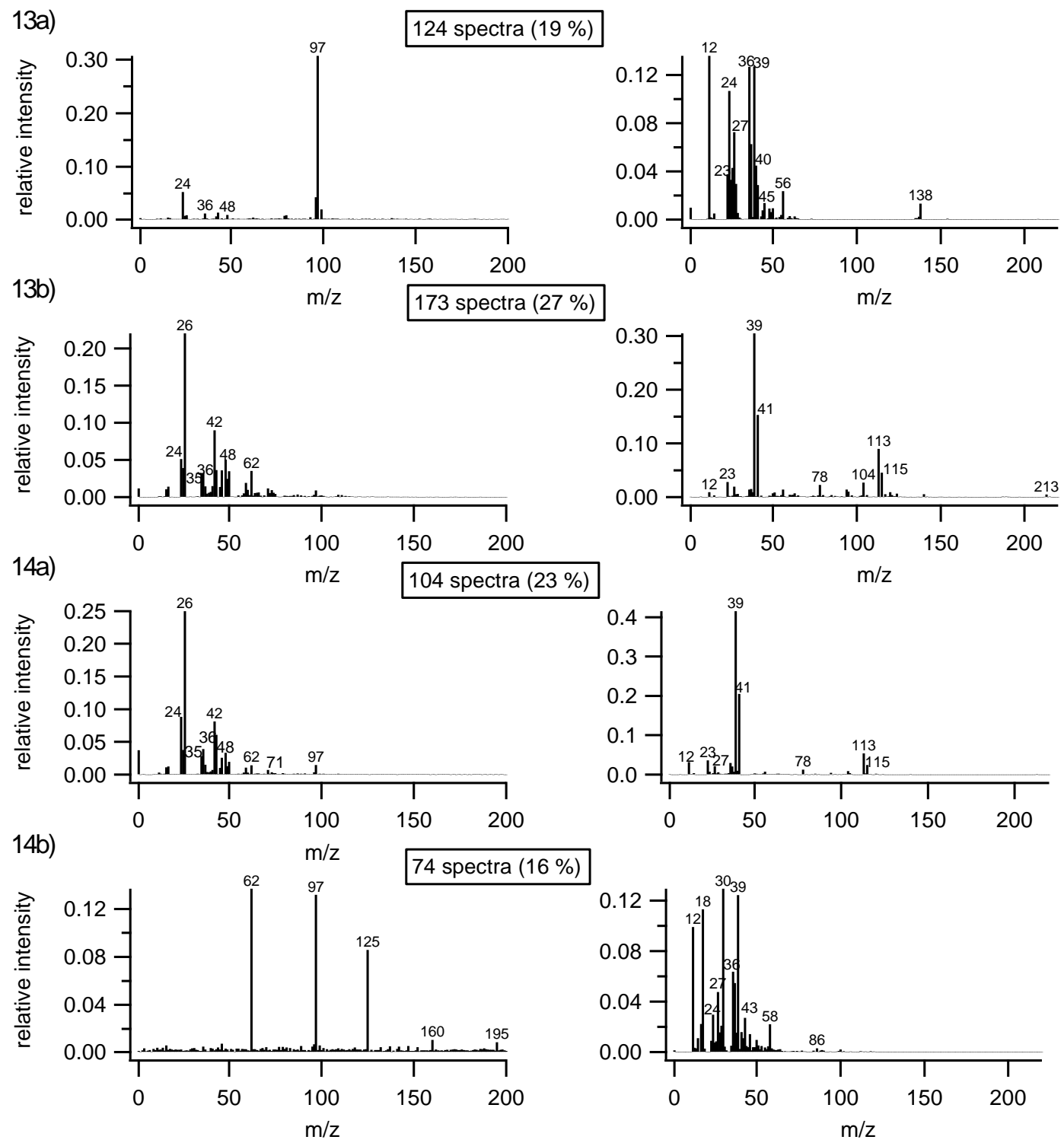

15)

$$
173 \text { Spektren (84 \%) }
$$
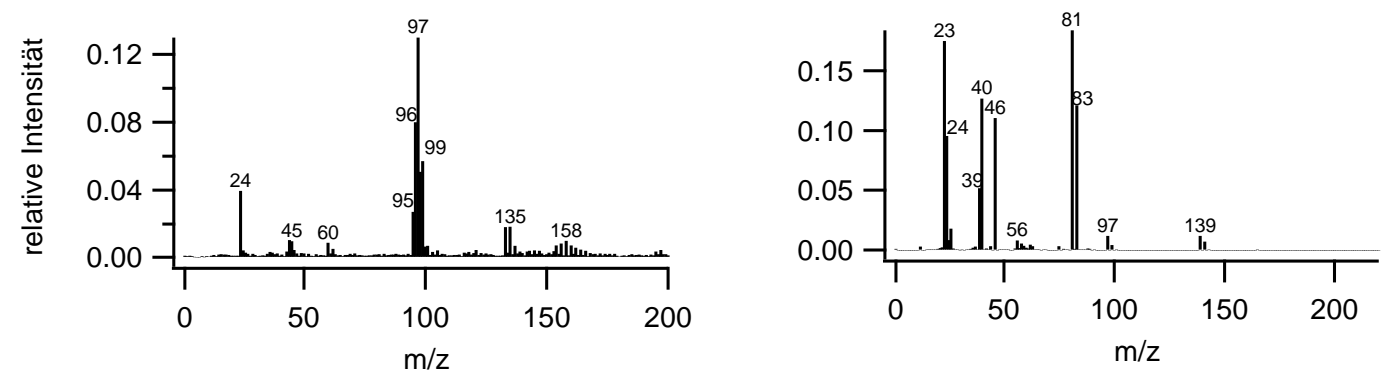

Figure S4: Average spectra of different substances of biological/natural origin from the laboratory measurements at MPIC: 13) fiber cellulose; 14) microcrystalline cellulose; 15) sea salt. 

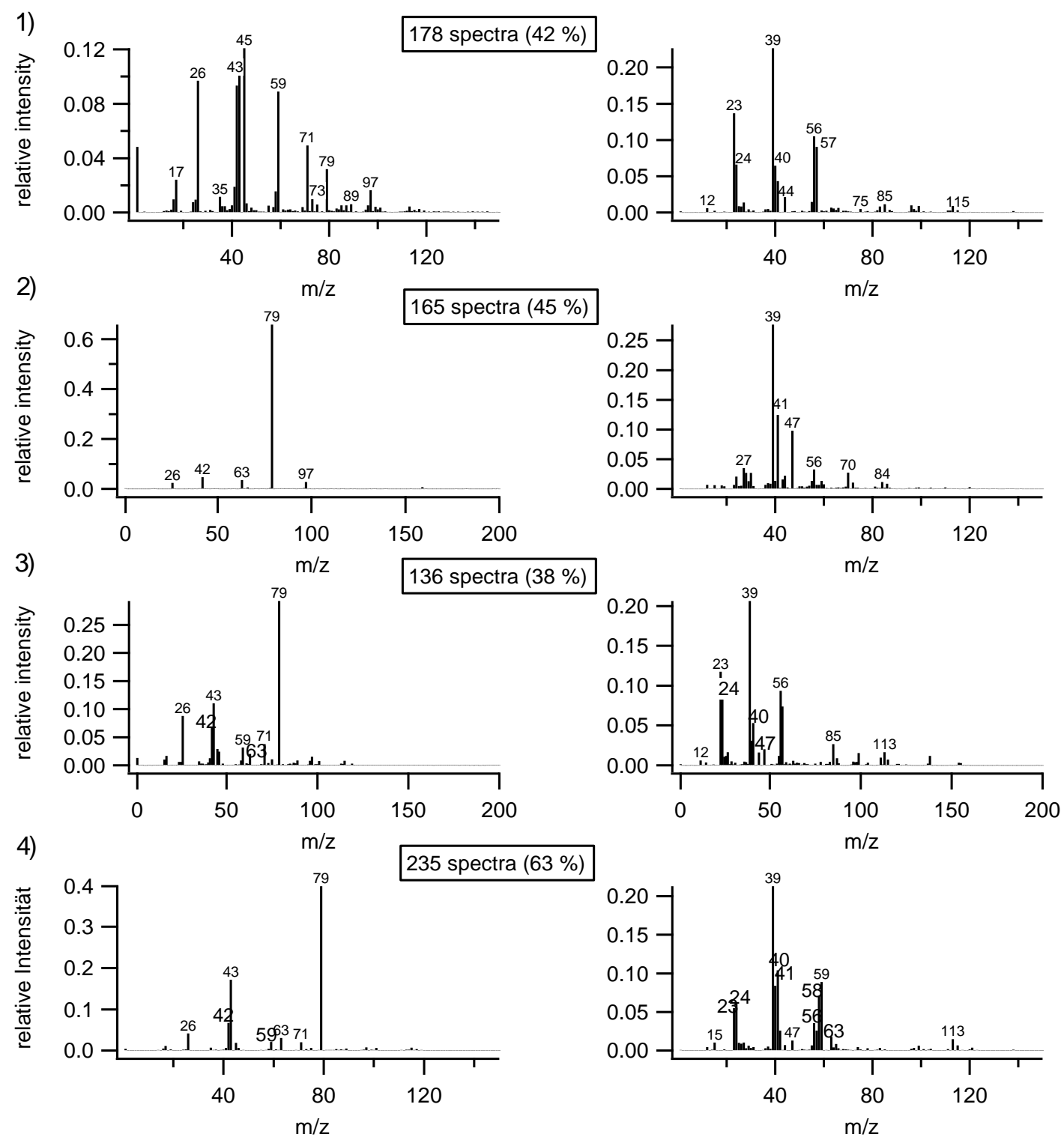

Figure S5: Average spectra from the investigation of different types of pollen from the laboratory measurements at MPIC: 1) birch; 2) hazel nut; 3) pine; 4) rye. 
1a)
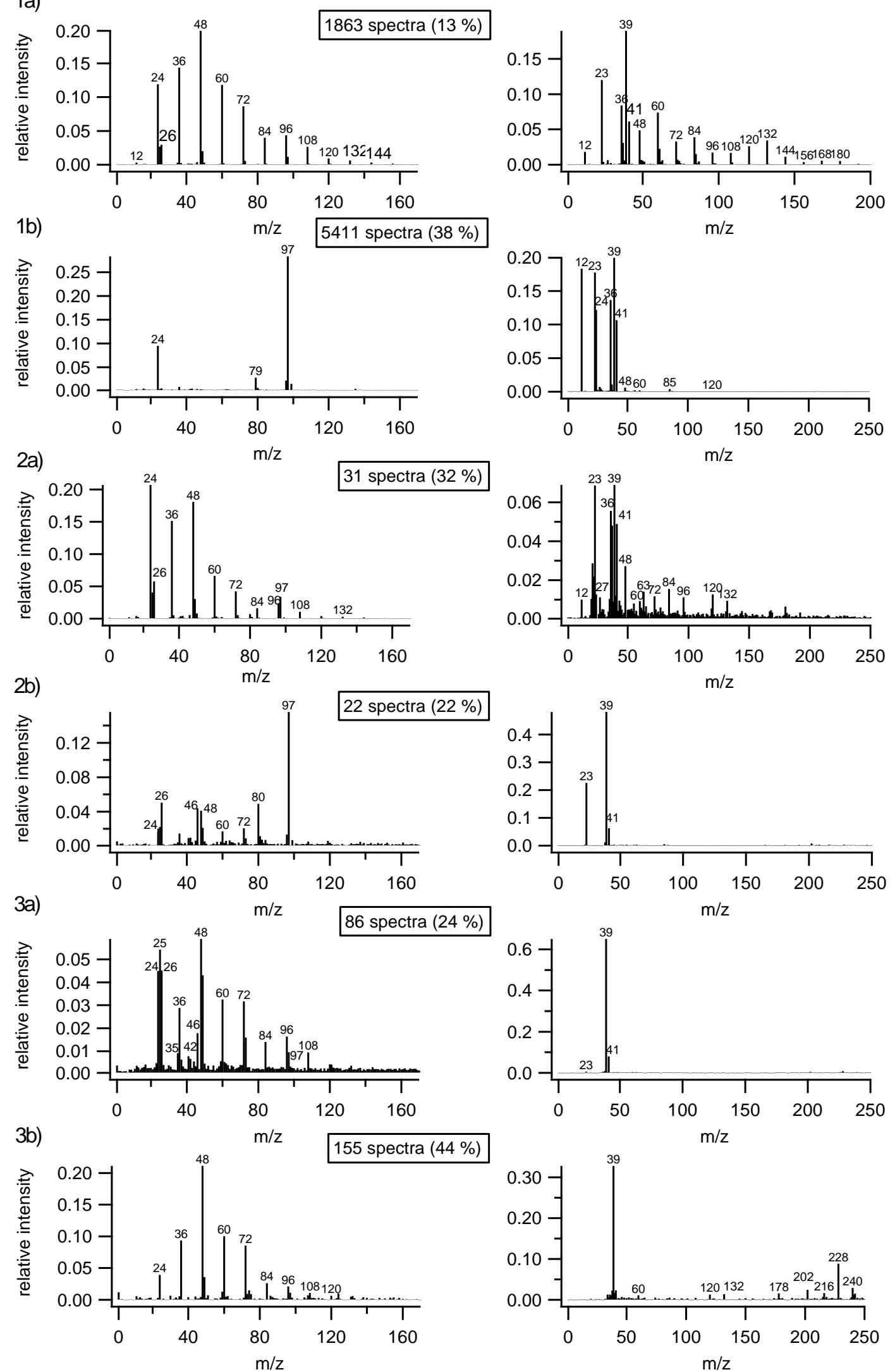

Figure S6: Average spectra of biomass burning particles from the laboratory measurements at MPIC: 1) bangkirai; 2) brown coal; 3) beech. 

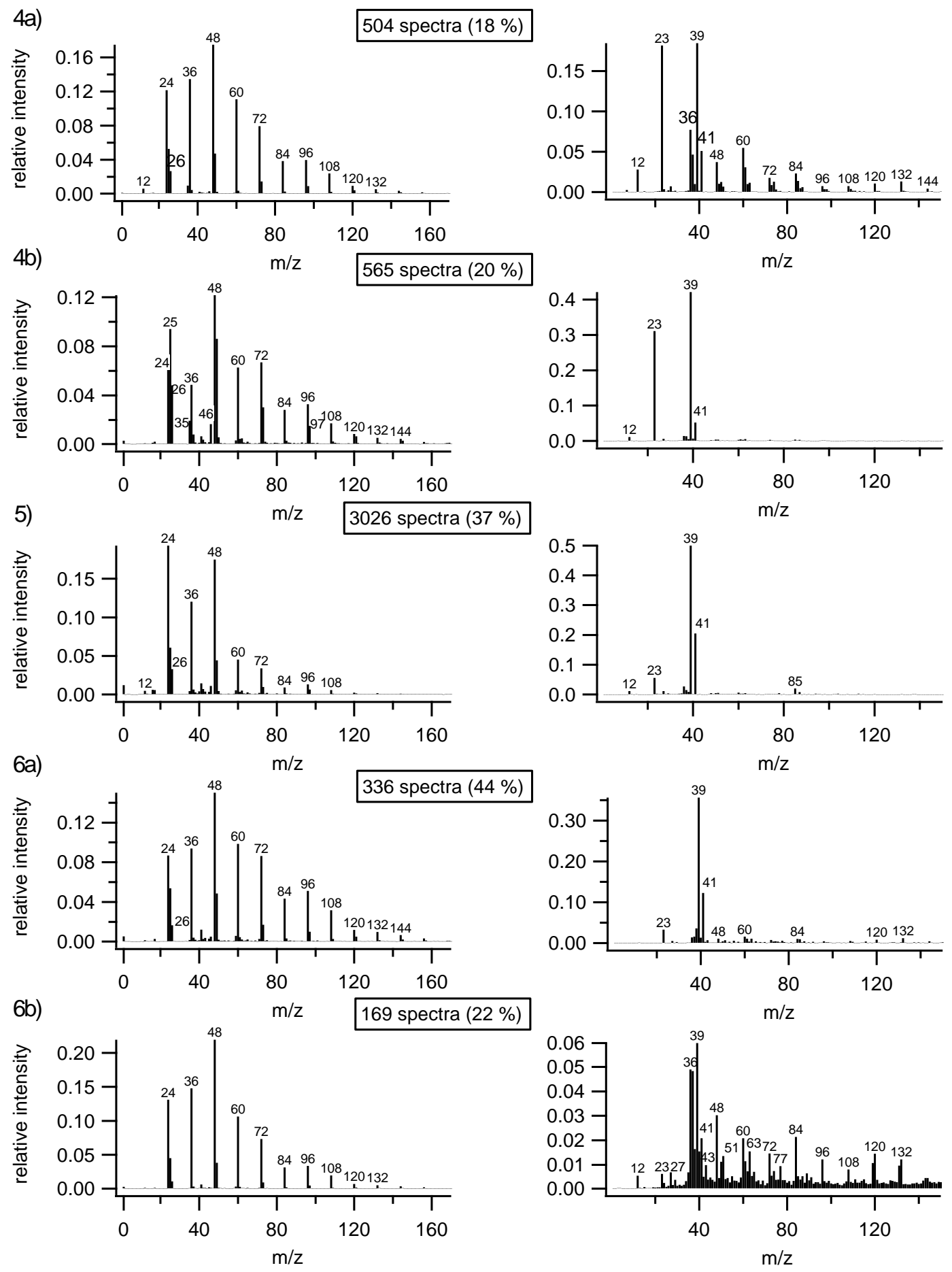

Figure S7: Average spectra of biomass burning particles from the laboratory measurements at MPIC: 4) euro pallet; 5) spruce; 6) pine. 

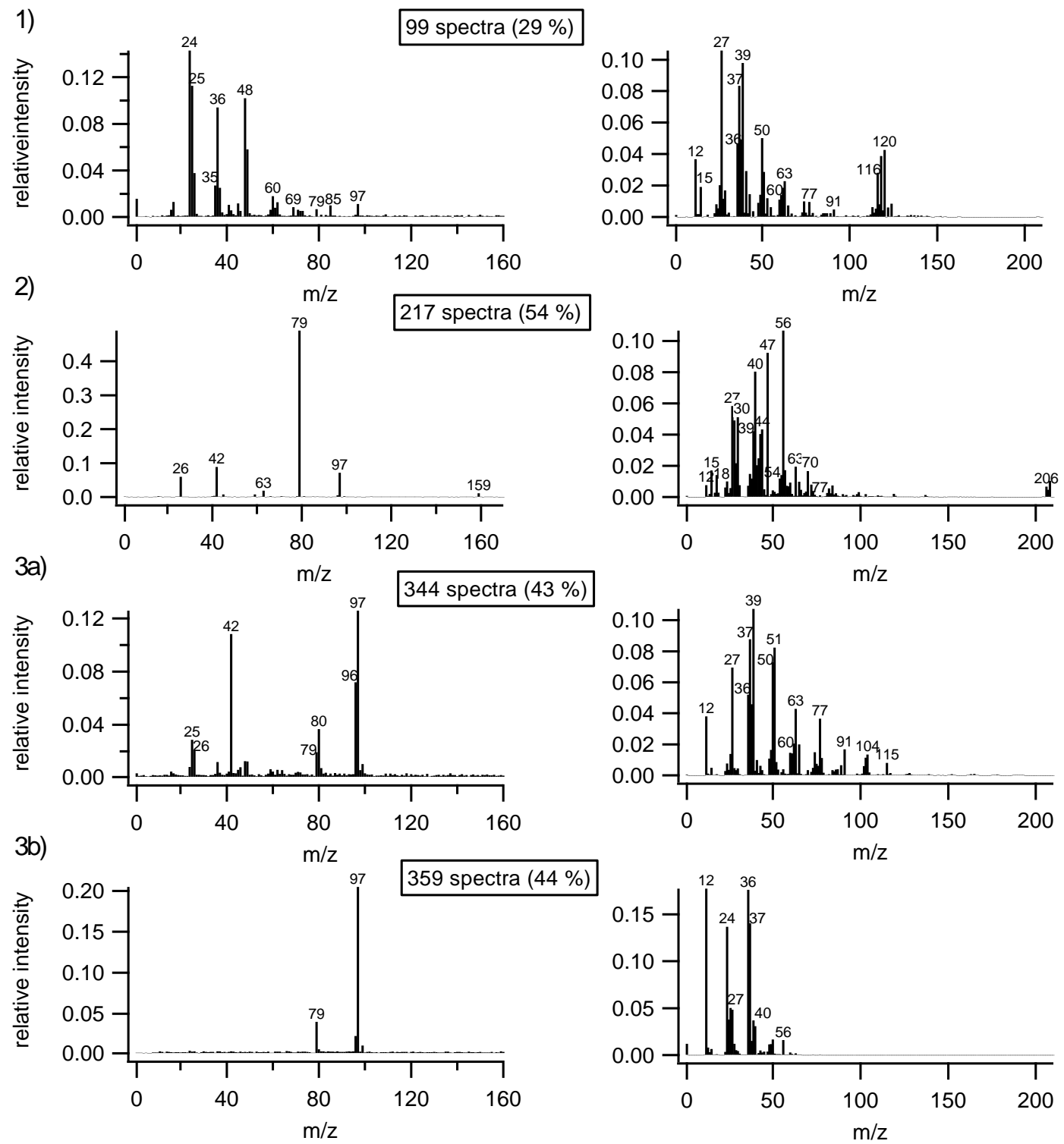

Figure S8: Average spectra of different PAHs from the laboratory measurements at MPIC: 1) benzo[ghi]perylene; 2) dibenzo(a,h)anthracene; 3 ) triphenylene. 
4a)
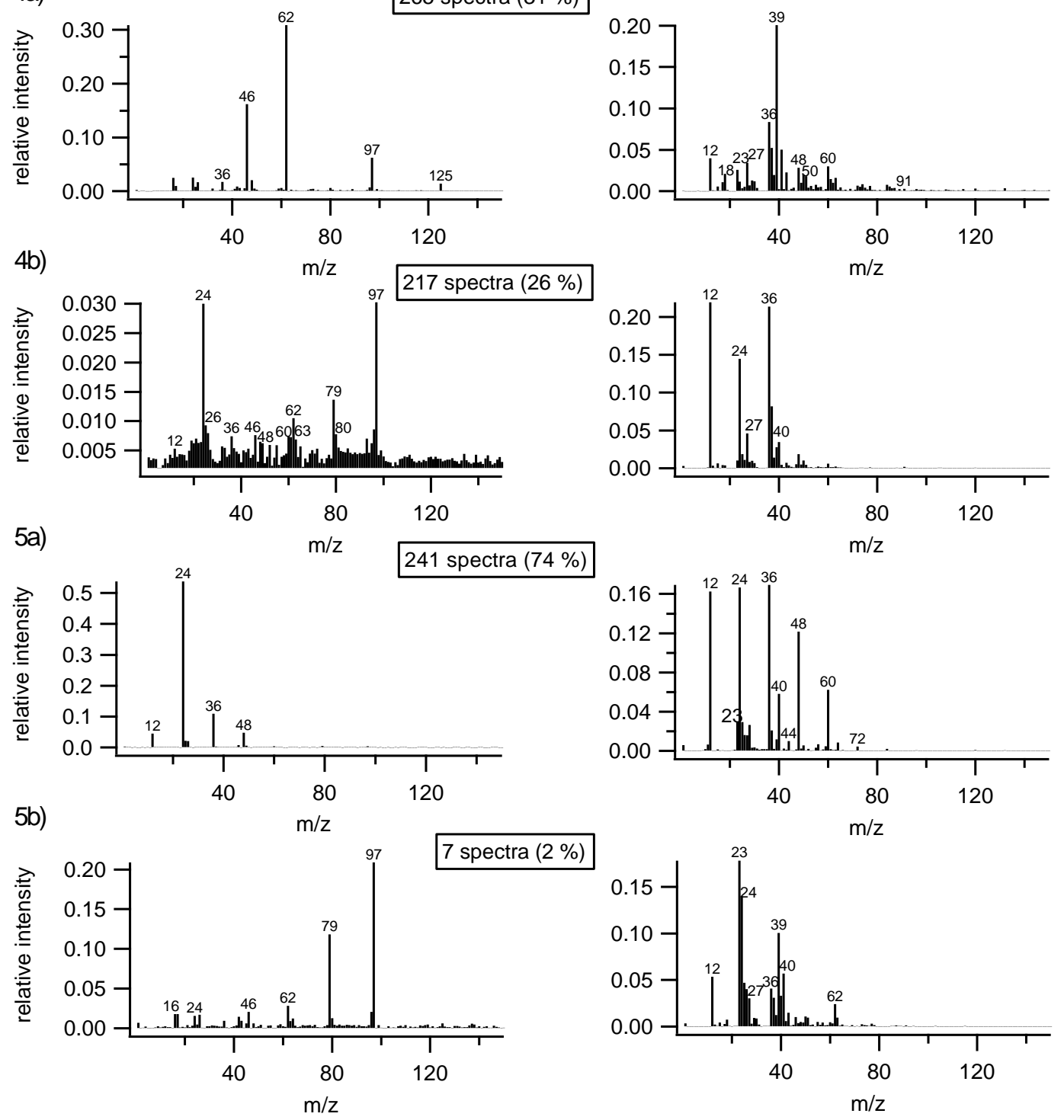

Figure S9: Average spectra of fuel exhaust particles from the laboratory measurements at MPIC: 4) fuel exhaust; 5) incomplete combustion of fuel exhaust. 

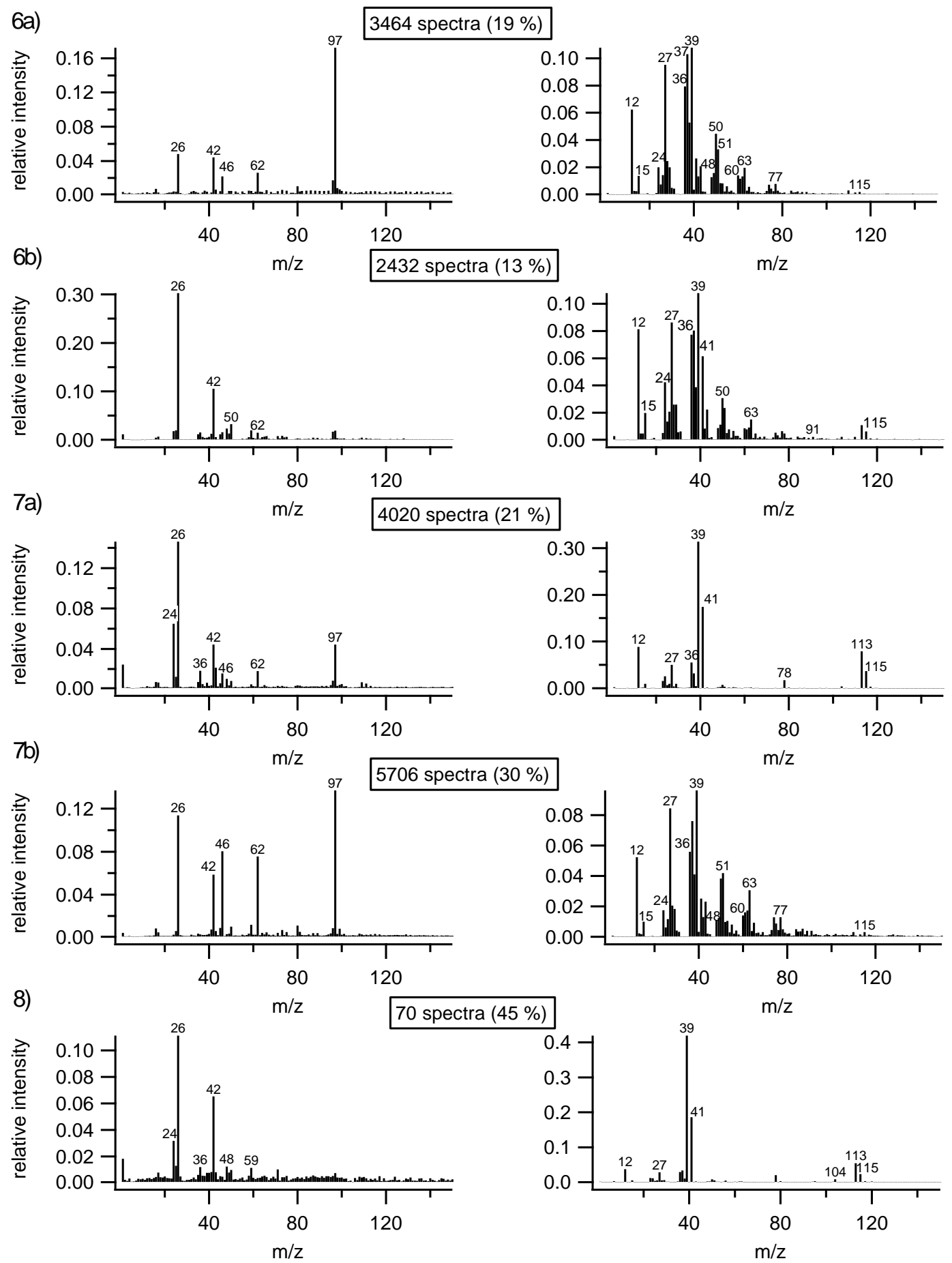

Figure S10: Average spectra of particles from cigarette smoke from the laboratory measurements at MPIC: 6) cigarettes with additives; 7) cigarettes without additives; 8) airborne measurement from cigarette smoke without measurements. 

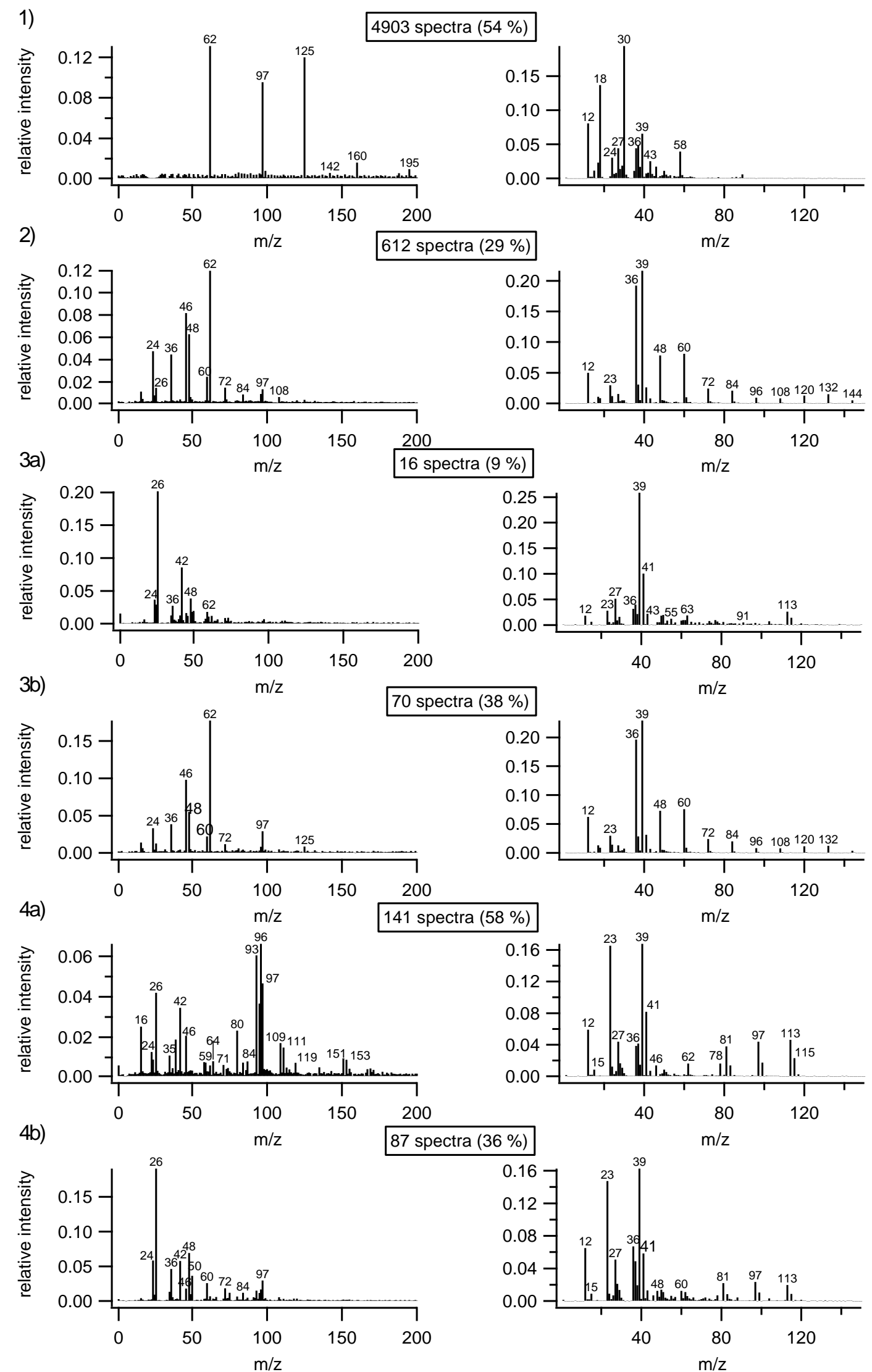

Figure S11: Average spectra of particles from cook emissions/barbecue from the laboratory measurements at MPIC: 1) background aerosol; 2) spilling of coal; 4) heating of the coal; 5) barbecuing of cheese. 

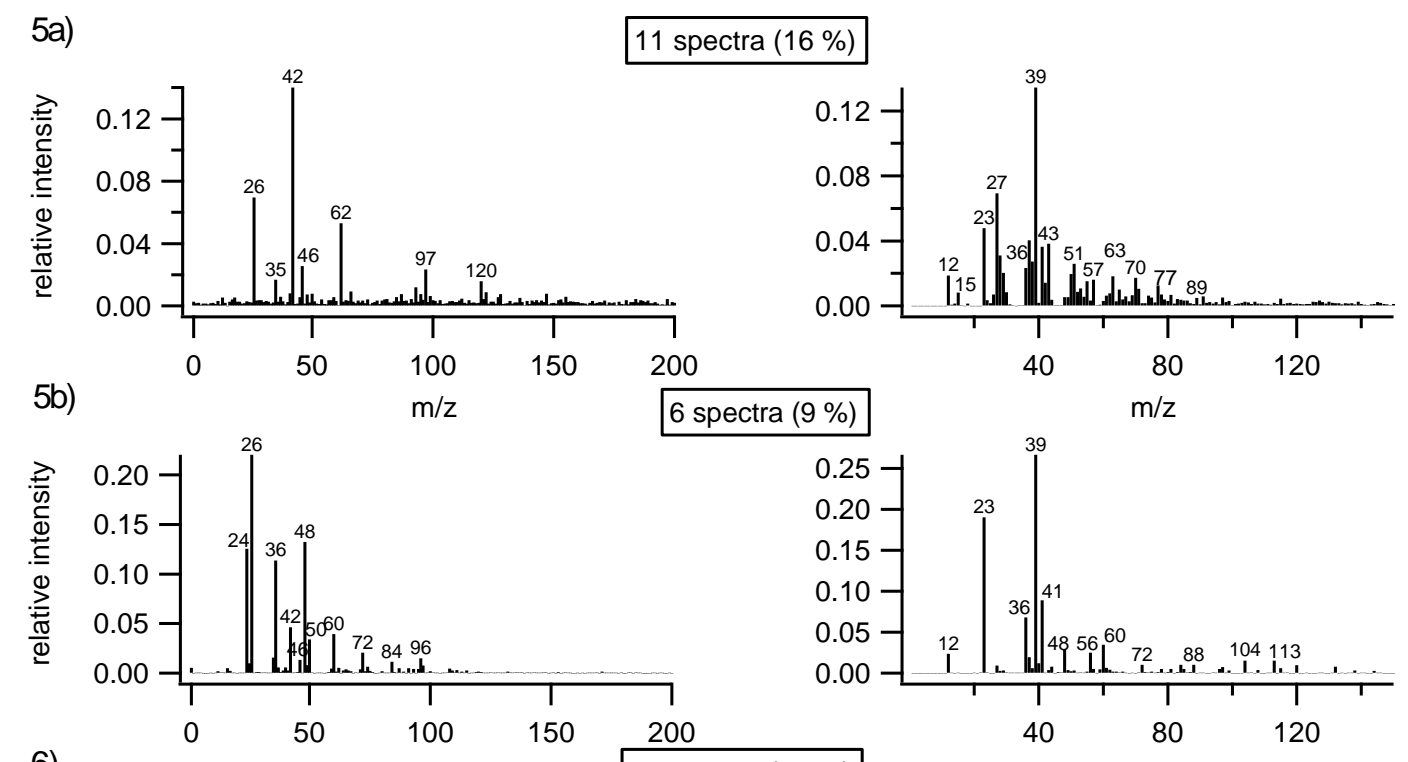

spectra $(9 \%) \quad \mathrm{m} / \mathrm{z}$
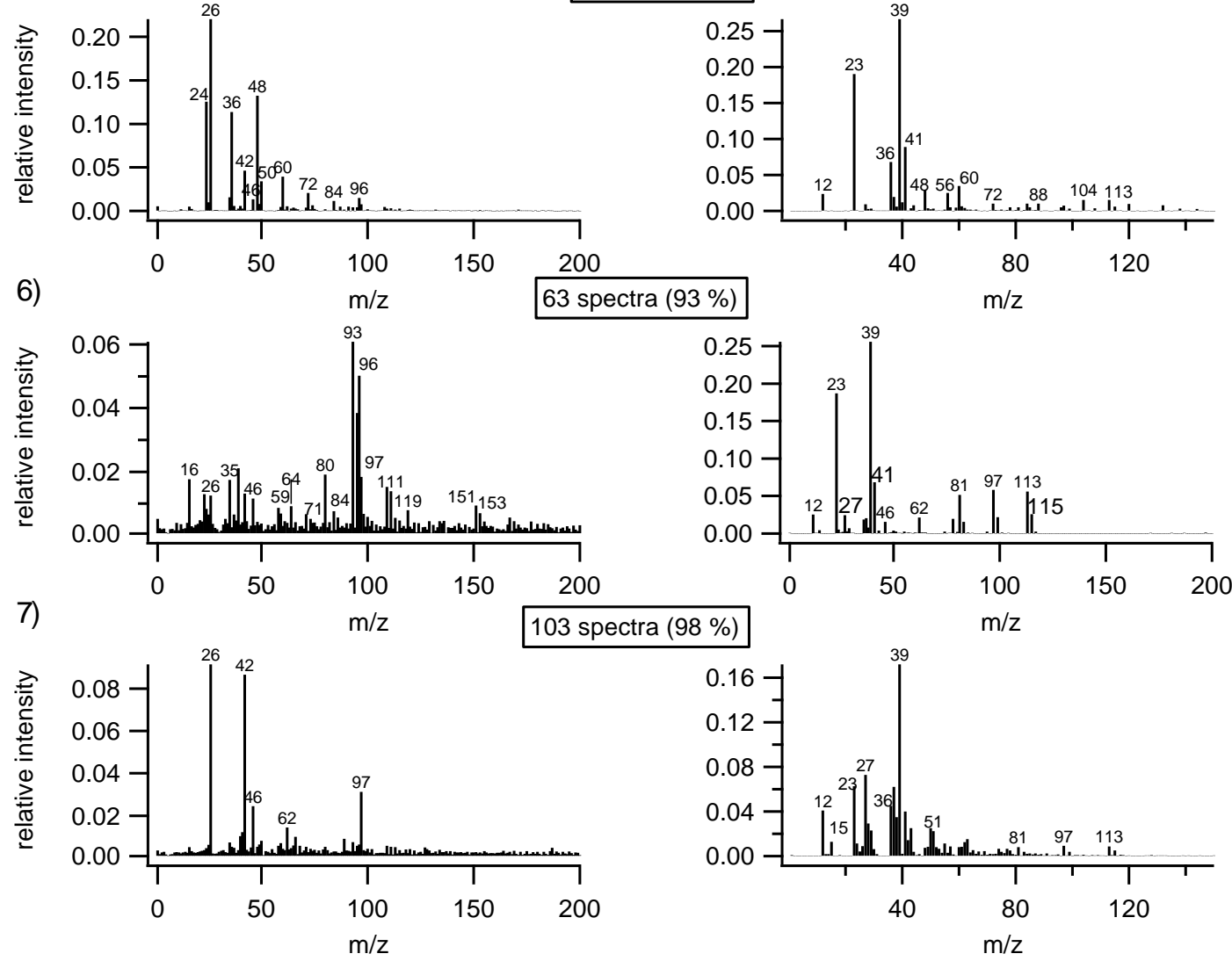

Figure S12: Average spectra of particles from cook emissions/barbecue from the laboratory measurements at MPIC: 5) barbecuing of sausages (smooth); 6) barbecuing of sausages (coarse); 7) barbecuing of steak. 
1a)

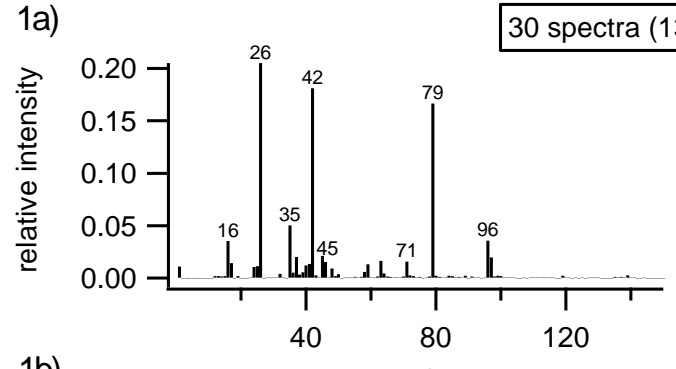

1b)

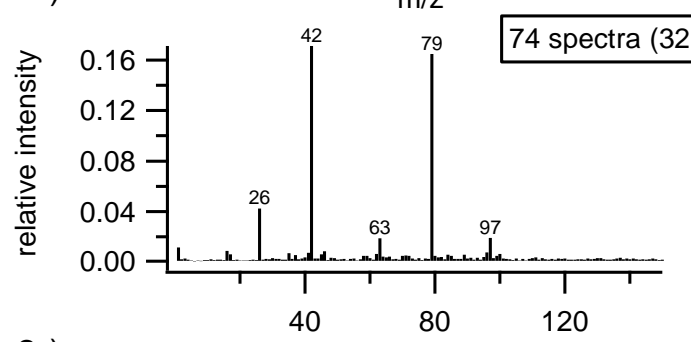

2a)

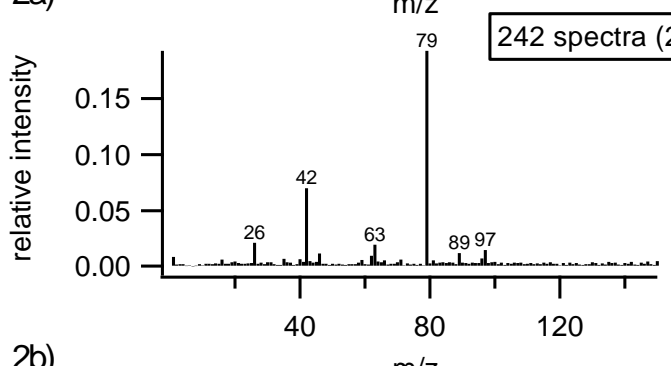

2b)

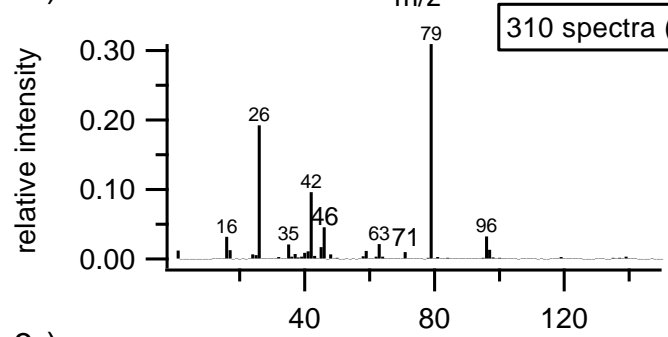

3a)

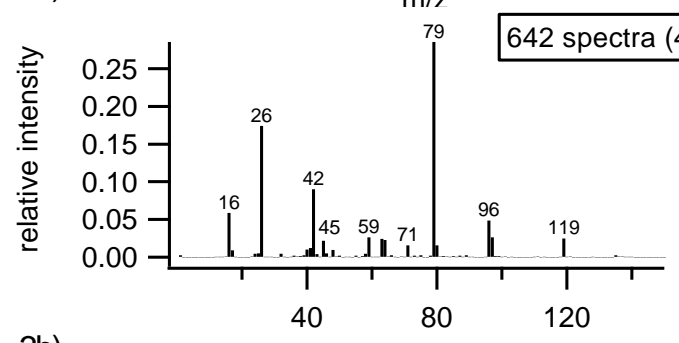

3b)

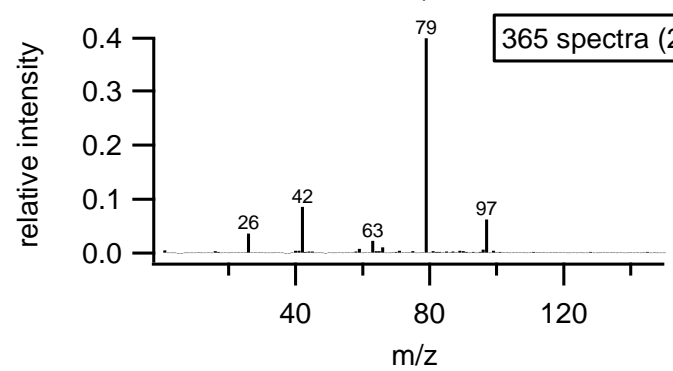

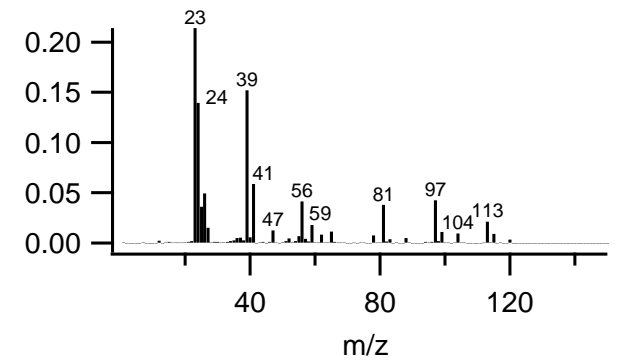
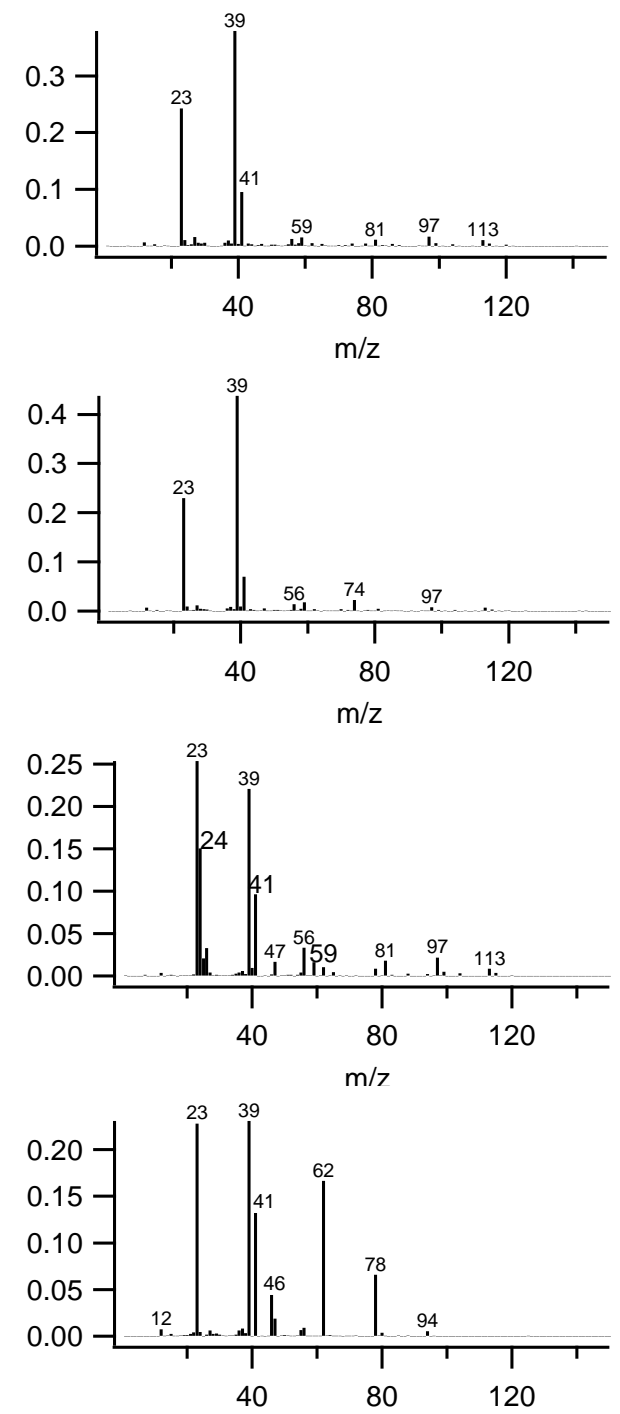

$\mathrm{m} / \mathrm{z}$

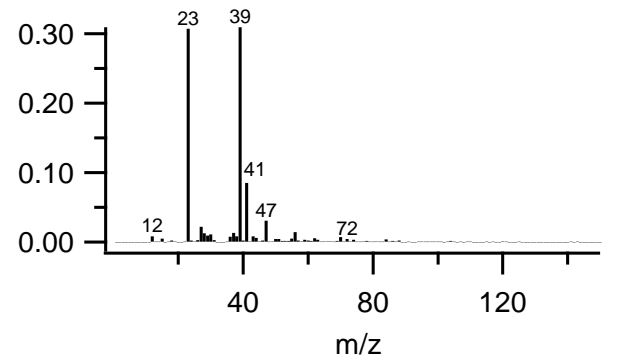

Figure S13: Average spectra of different bacteria types from the laboratory measurements at the AIDA:

1) PS-32b-74; 2) PF-CGina; 3) Snomax ${ }^{\circledR}$. 

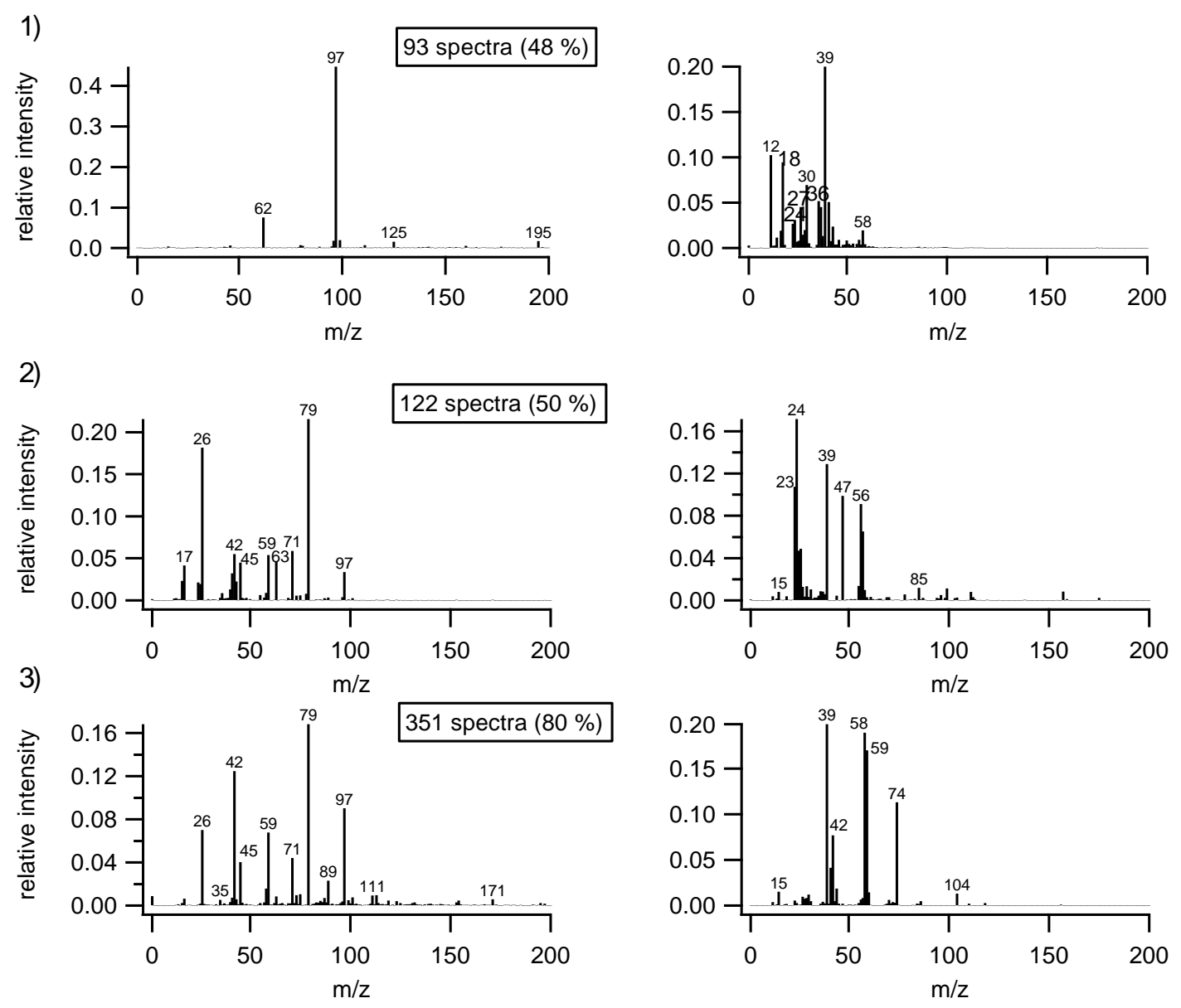

Figure S14: Average spectra of ground leaves and two different types of pollen from the laboratory measurements at the AIDA: 1) maple leaves; 2) birch pollen; 3) sun flower pollen. 

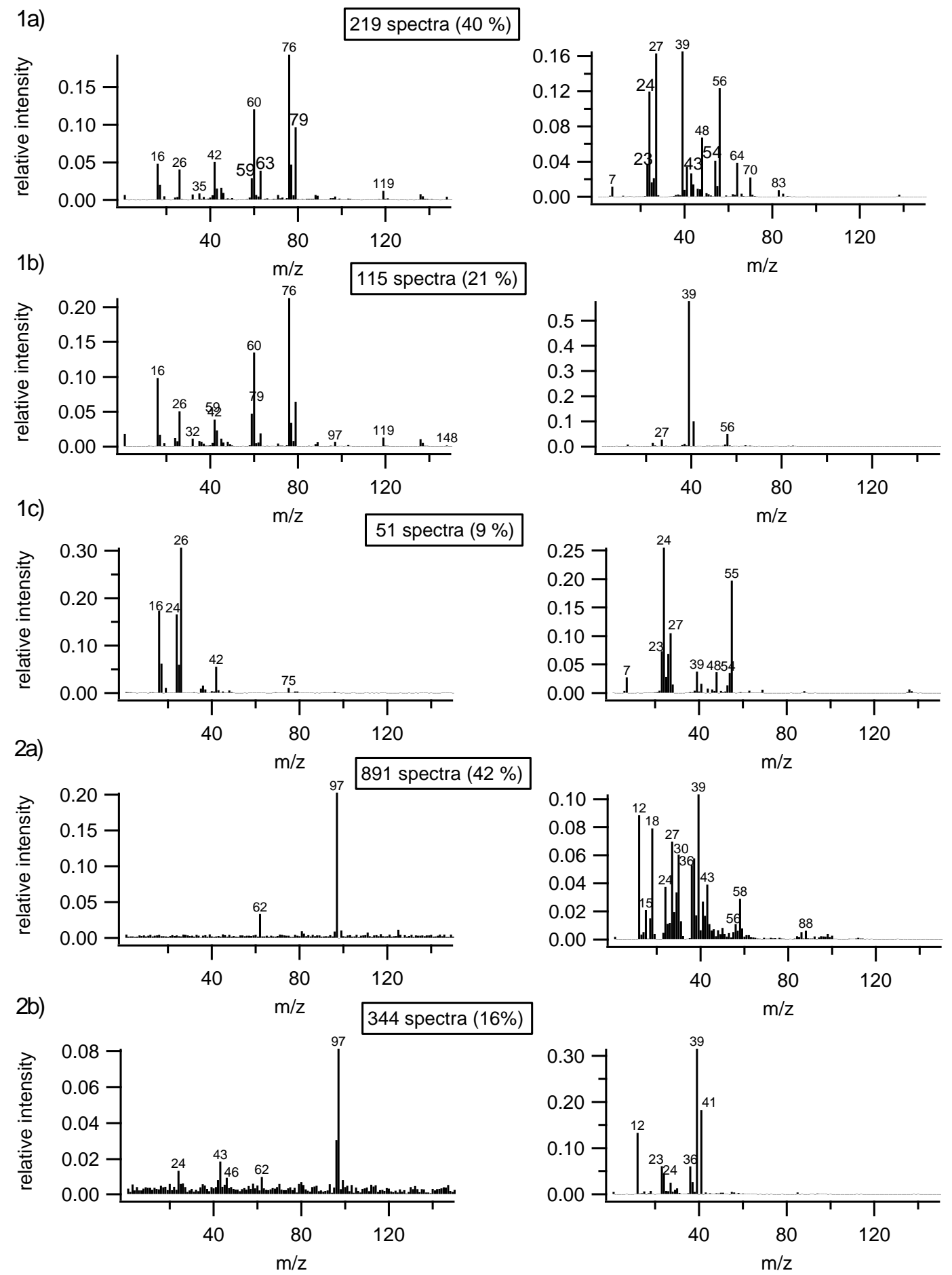

Figure S15: Average spectra of soil dusts with different origins from the laboratory measurements at the AIDA: 1) Argentina; 2) Switzerland. 

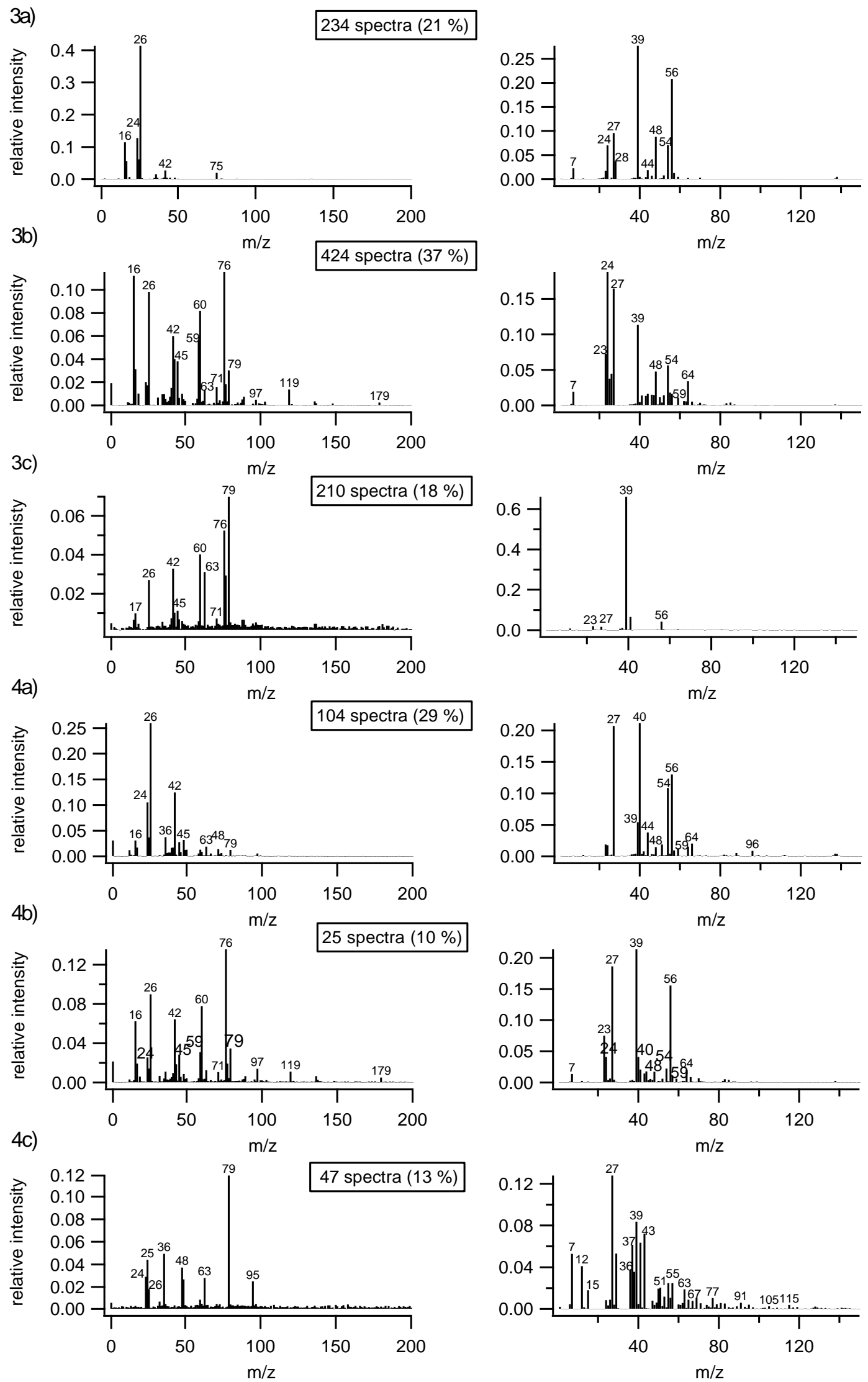

Figure S16: Average spectra of soil dusts with different origins from the laboratory measurements at the AIDA: 3) China; 4) Germany. 


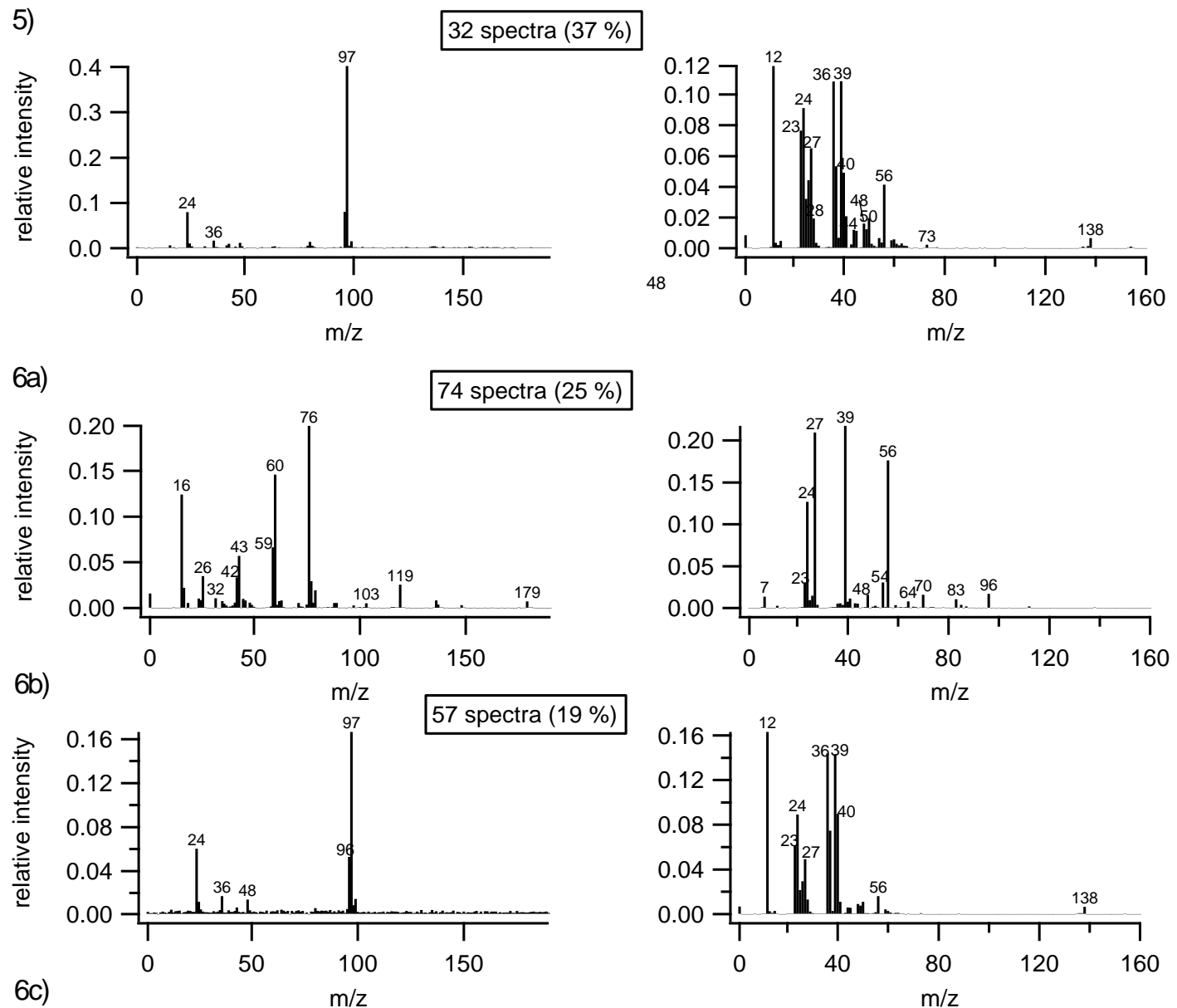

$6 c)$
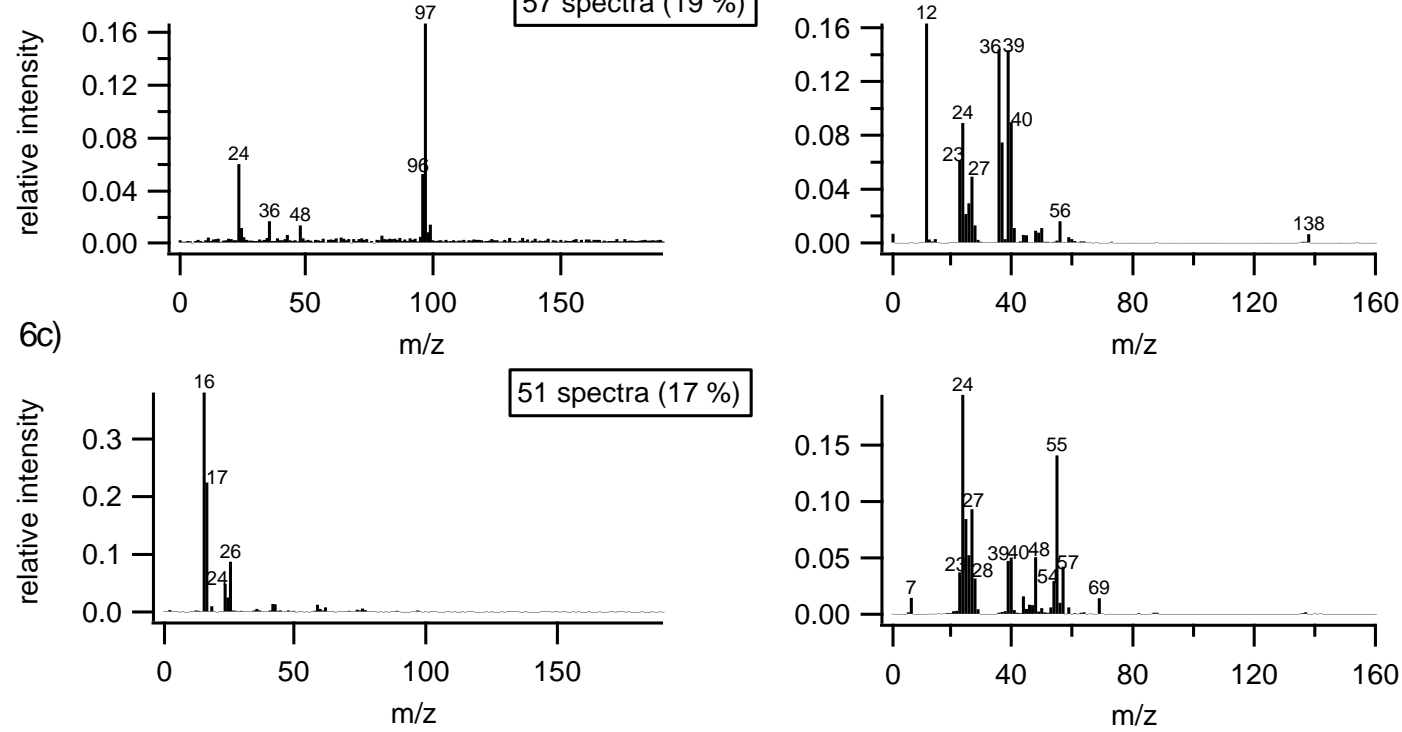

Figure S17: Average spectra of different types of dust from the laboratory measurements at the AIDA: 5) Ethiopian (volcanic dust); 6) Morocco (desert dust). 

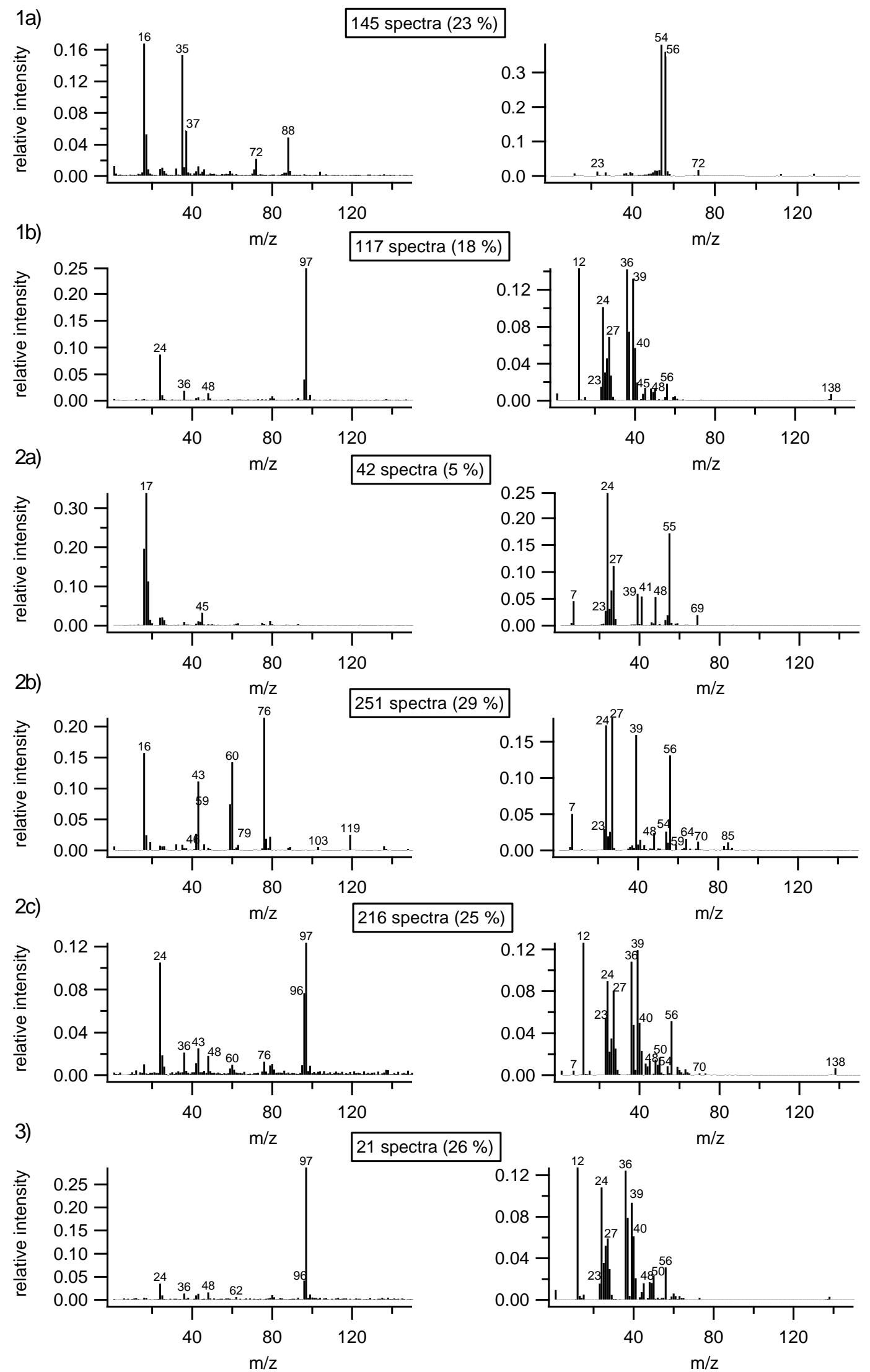

Figure S18: Average spectra of different types of minerals from the laboratory measurements at the AIDA: 1) Hematite 2) Illite; 3) Kaolinite. 
4a)

357 spectra $(61 \%)$
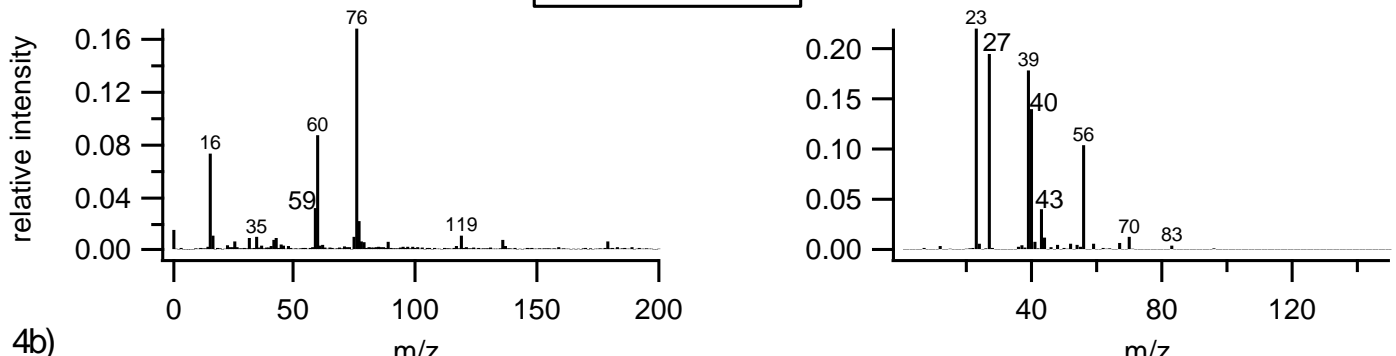

4b)

$\mathrm{m} / \mathrm{z}$

66 spectra $(11 \%)$

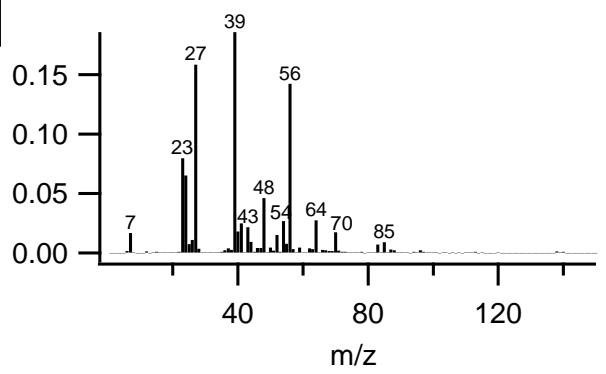

Figure S19: Average spectra of Feldspar (FS05; Na-rich) from the laboratory measurements at the AIDA. 

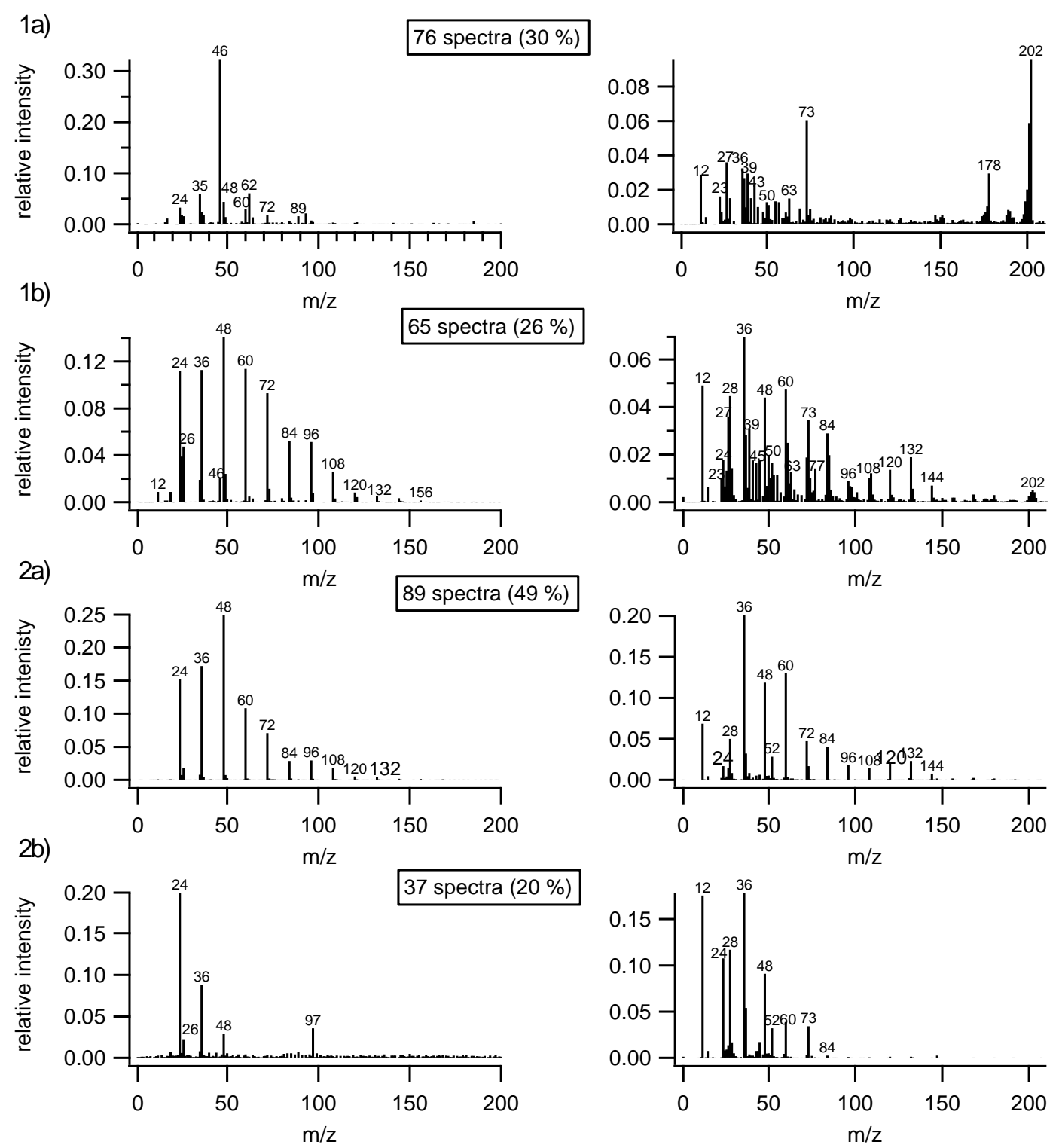

Figure S20: Average spectra of two different types of soot from the laboratory measurements at the AIDA: 1) CAST; 2) GSG. 